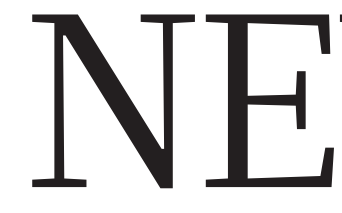

GEOSCIENCE Cooking up a model of Earth's core in the laboratory p.162
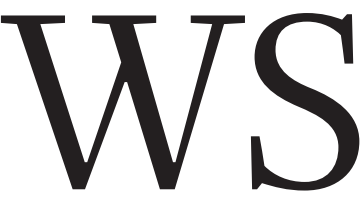
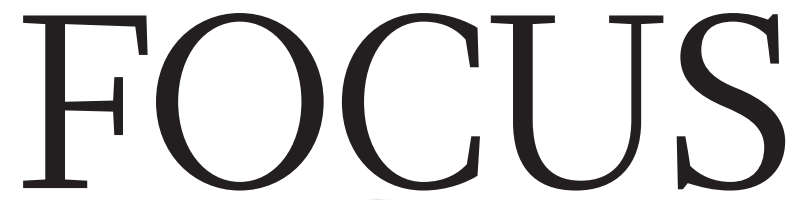

1

EDUCATION Will cuts sacrifice excellence at the University of California? p.164
OCEANOGRAPHY China's ambitions ride a spanking new ship p.166
PROFILE Henrik Ehrsson

probes the mind with body illusions $\mathbf{p} .168$

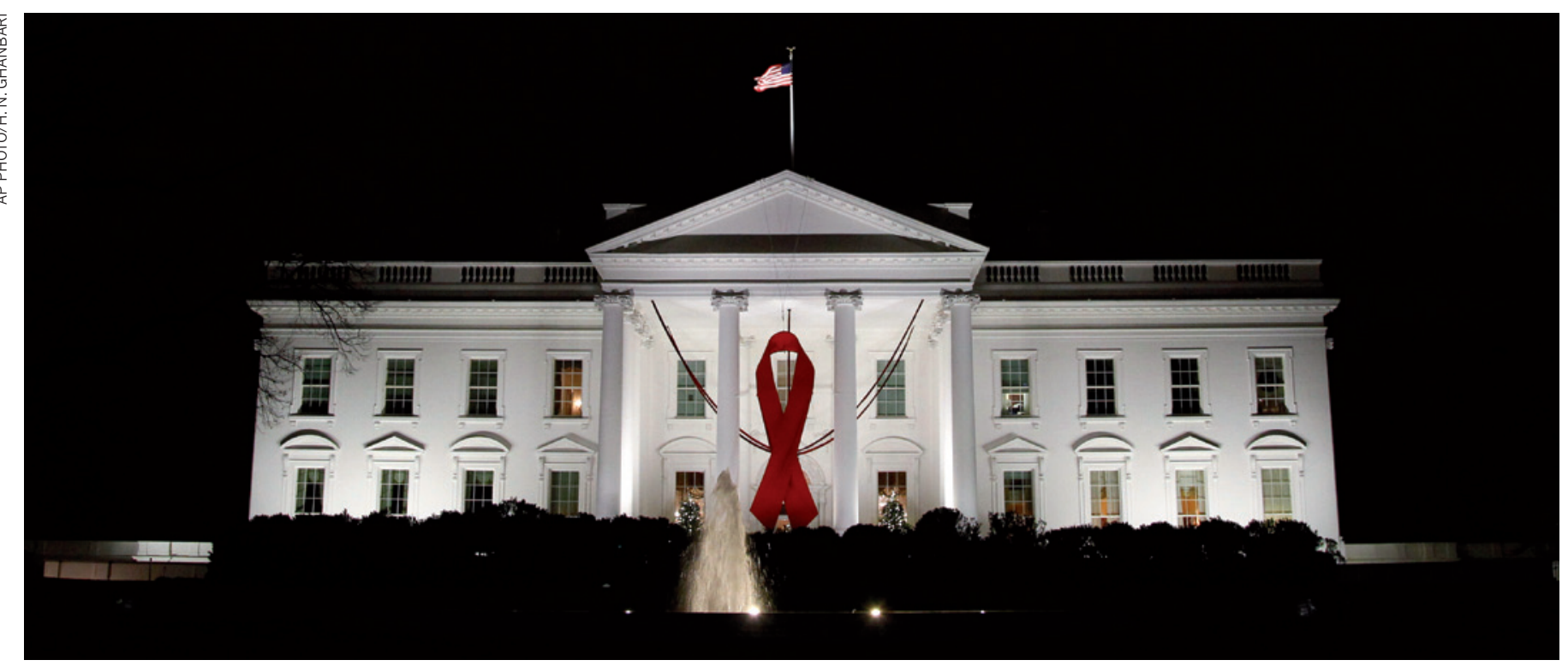

US President Barack Obama last week pledged to fund HIV treatment for millions more people worldwide over the next two years.

GLOBAL HEALTH

\title{
Cutbacks threaten HIV gains
}

\section{Wealthy nations have reduced contributions to global research and treatment programmes.}

\section{BY MEREDITH WADMAN}

$\mathrm{T}$ Thirty years after AIDS was first recognized as a human scourge, major recent gains in treatment and prevention risk being derailed by the global financial crisis.

On 23 November, the Global Fund to Fight AIDS, Tuberculosis and Malaria announced that it will not fund new grants for prevention and treatment until 2014, owing to "substantial budget challenges in some donor countries". The fund's HIV activities run the gamut from counselling and testing pregnant women in India to providing medications to infected children in Kenya.

And on 7 December, a report from Policy Cures in Sydney, Australia, a group that monitors global research and development for neglected diseases, showed that public and private funders last year cut their commitments to HIV/AIDS research targeted at the developing world by US $\$ 67.5$ million, or $5.9 \%$. The decline was due entirely to cutbacks by wealthy nations, which slashed spending by $\$ 72.6 \mathrm{mil}-$ lion; poorer countries actually increased funding by $\$ 5.1$ million. Where research is concerned, "AIDS had a bigger drop in dollar terms than any other disease", says Mary Moran, the executive director of Policy Cures and the lead author on the report.

The threat comes even as US President Barack Obama last week promised that the United States will step up its worldwide attack on AIDS. Breaking the White House's past reticence on the issue, he urged nations to honour their unmet pledges to the Global Fund.

"Countries that have committed to the Global Fund need to give the money that they promised," he said on 1 December, World AIDS Day. "Countries that haven't made a pledge, they need to do so," he added, singling out emerging nations such as China that are recipients of funds "but now are in a position to

\section{DNATURE.COM}

For more, see

Nature's Outlook on HIV/AIDS:

go.nature.com/ms4u9t step up as major donors".

The United States has given $\$ 6.1$ billion to the Global Fund since 2004, and last year pledged to contribute $\$ 4$ billion between 2011 and 2013. Congress approved $\$ 1.05$ billion in 2011, meaning that allotments must increase substantially in 2012 and 2013 to honour the pledge. Obama has asked Congress to provide $\$ 1.3$ billion in 2012, but Senate lawmakers have so far resisted the increase.

Obama pledged to increase by $50 \%$ - to 6 million - the number of people receiving antiretroviral therapy (ART) worldwide by 2013 through the President's Emergency Plan for AIDS Relief (PEPFAR), the nation's major global treatment and prevention programme. He also said PEPFAR would aim to provide ART to an additional 1.5 million pregnant women with HIV in the next two years. The international promises came with no new money immediately attached. But Obama has asked Congress to provide nearly $\$ 7.2$ billion - a $6 \%$ increase - for PEPFAR in 2012, part of the 
unfinished budget bills still being debated.

Advocates said that his speech marked a significant turning point. "This is the first time he's signalled that he's going to champion global HIV in this way," says Jennifer Cohn, an assistant professor of infectious diseases at the University of Pennsylvania in Philadelphia, and a policy adviser in Nairobi for Médecins Sans Frontières (MSF; also known as Doctors Without Borders). "Whether or not this gets translated into the president's 2013 budget request, or what Congress chooses to protect during the 2012 budget negotiations - that's what I'm waiting to hear."

Even if the United States manages to expand treatment for HIV/AIDS, research and development aimed at poor countries is suffering. Moran points out that of the $\$ 67.5$ million cut from HIV/AIDS research spending in 2010, $\$ 32$ million was due to cuts by the US National Institutes of Health, and a further \$17 million was cut by the UK Department for International Development (see 'Fighting a killer'). Other neglected diseases are seeing similar reductions in research funding (see go.nature.com/sgv7oj).

"A lot of this reflects the financial crisis, that's undoubted," Moran adds. "But with HIV, some of it also reflects a shift from the more costly late-stage vaccine and microbicide trials that haven't worked. We are moving back to basic research, which is cheaper."

The cutbacks coincide with encouraging results on HIV/AIDS treatment. One study published in August found that early treatment of those infected greatly decreases sexual transmission to their uninfected partners, (M. S. Cohen et al. N. Engl. J. Med. 365, 493-505; 2011). Other recent work suggests that ART, although costly, will pay for itself and more by increasing labour productivity, reducing the need for orphan care and deferring

\section{FIGHTING A KILLER}

Funding for research and development (R\&D) of HIV/AIDS products targeted at developing countries fell last year, whereas treatment with antiretroviral therapies has grown rapidly over the past decade.

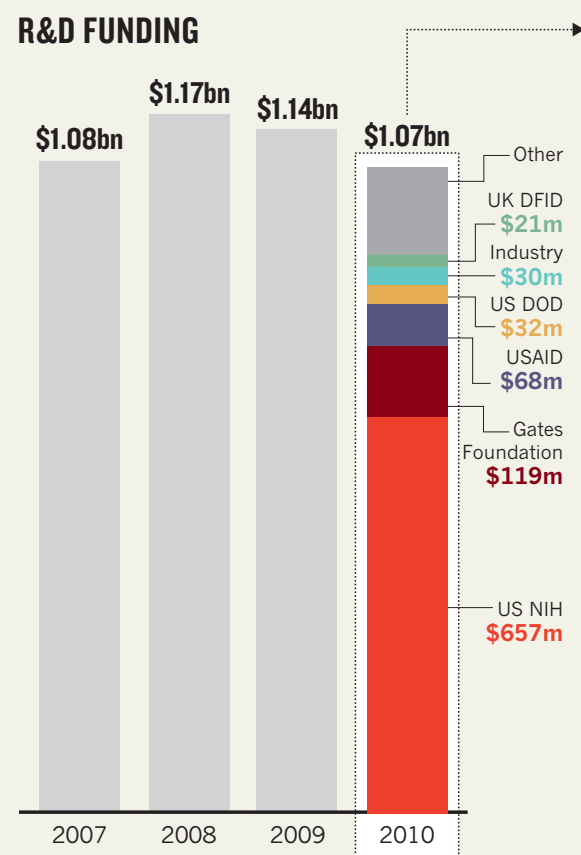

$\rightarrow$ RESEARCH

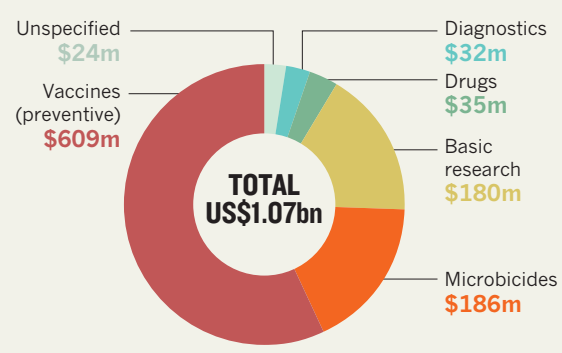

ANTIRETROVIRAL THERAPY

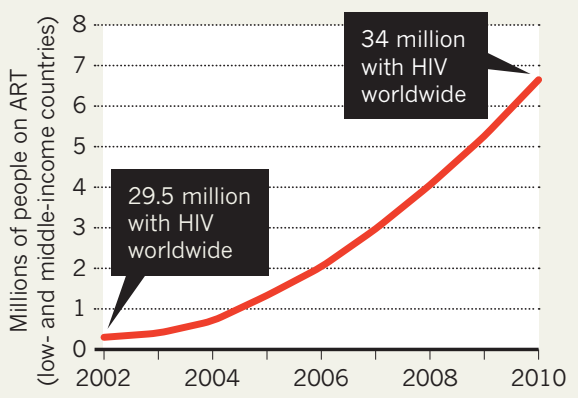

Figures are adjusted for inflation and reported in 2007 US dollars. ART, antiretroviral therapy; DFID, Department for International Development; DOD, Department of Defense; NIH, National Institutes of Health; USAID, US Agency for International Development.

medical treatment costs (S. Resch et al. PLoS ONE 6, e25310; 2011). "Not only is [treatment] the right thing to do, it's also the smart thing to do," says Sharonann Lynch, an HIV policy adviser with MSF in New York.

But the 'treatment equals prevention' equation invoked by Obama is not selling in all quarters. Roger Bate, a health economist and HIV expert at the American Enterprise Institute, a think tank in Washington DC, says that he is not yet persuaded by the studies suggesting that treatment prevents transmission. "There is a lot of effort out there to ignore noise in those studies," he says.

He adds that, even if treatment does prevent transmission, the commitment to treat infected people for their lifetimes quickly becomes an enormous financial outlay in future years. "Is it sustainable to treat even more people under current budgets?" he asks. "I don't think it is."

\section{Nano rules fall foul of data gap}

\section{Incomplete nanotoxicology research is hampering efforts to introduce regulation.}

\section{BY EUGENIE SAMUEL REICH}

$\mathrm{T}$ The science of the very small will lurk in many a Christmas gift this year. Nanomaterials add strength to golf clubs, odour resistance to socks and ultraviolet protection to cosmetics. But some of their properties could also pose health risks, and regulations covering their manufacture and use have failed to keep pace with the rush to market.

With sizes measured in mere billionths of a metre, nanomaterials have very high surface area relative to their mass, and this could alter their toxicity compared with the same material in bulk. Yet many nanomaterials are not regulated separately - in part because the high-quality nanotoxicity research needed for regulation is lacking, as an assessment presented at last week's Materials Research Society meeting in Boston, Massachusetts, made clear.

Groups representing food manufacturers had asked Cantox Health Sciences International, a consultancy in Mississauga, Canada, to review the literature for studies that could shed light on the effects of consuming nanoparticles from food packaging, in which they may be used to improve strength or even detect spoilage.

Cantox sampled 30 papers describing studies in which nanoparticles were fed to animals or applied in vitro to cells of the gastrointestinal tract. Of 21 animal studies, the Cantox researchers found that 15 failed to attain the highest grade on the Klimisch test, a qualitycontrol criterion that assesses whether basic data, such as the number or gender of animals used, have been reported. "Some didn't give the dosage. This is a fairly important aspect," says Jeffrey Card, a toxicologist at Cantox who led the study.

The underlying materials science was equally spotty. Of 10 parameters that Cantox concluded should be reported in a nanotoxicity 